\title{
Reflections on a decade of HIV in my life
}

C Friend, MB ChB, DipHIVMan

Corresponding author: C Friend (chantelfriend@gmail.com)

Chantél Friend is affiliated with the Qhakaza Mbokodo Research Centre, Ladysmith, KwaZulu-Natal, South Africa

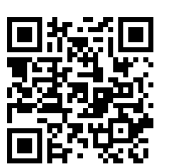

The red HIV ribbon is an almost universal icon for the HIV/AIDS cause. I see the HIV ribbon in four different ways as I reflect on the different periods of work in my medical career thus far. Firstly, I see the red ribbon upside down, just like my head was firmly ostriched in the ground soon after qualifying in the Western Cape. There was one ward right at the top, out of the way of a medical intern's rounds, where all those patients went to die and at least I didn't need to worry about a 'resus' in that ward. But, towards the end of 2003, my interest was piqued when a few of the respected medical officers were heading towards HIV care. That was forgotten though when I started private general practitioner work with not a single HIVpositive patient, until one routine insurance test came back positive - one devastated patient!

But then the ribbon turned on its side as I moved to the Eastern Cape and worked for a non-governmental organisation. The number of devastated patients there could not be counted. I quickly had to learn to swim in the deep sea of HIV treatment. There were days when I almost drowned, like the day I was summoned into a small room full of people and was called a racist for limiting (extraordinarily long) tea times in order to get through the patients first. As a team we thrashed it out in that dark room, and going forward we became a centre of excellence in our area, not only for our work, but also for our love for each other. We saw an entire town rally around us by providing soup, toys for the children, beautiful paintings and more. But most importantly, I saw life after HIV: a man on death's door walking back to work in a few months; a skeleton of a child smiling with her new toy after a few weeks of antiretrovirals; and Venus, who encouraged me at every consultation, despite being left blind and in a wheelchair after cryptococcal meningitis, and deserted by her family, but just managing to force the words out of her facial-palsied mouth, 'thank you'.

Thirdly, on moving to KwaZulu-Natal and working for the Department of Health, I turned the ribbon upright. A handful of doctors slaving away at the heart of the epidemic, seeing upwards of 80 patients a day. Clearly this was not sustainable, so we embraced nurse-initiated management of ART (NIMART). We worked within our crippled system, taking the literal 'iskoro skoro' (old broken car) on the road to the rural areas in our district to present our hopeful plan to all the clinics. And, lo and behold, it worked! This gave us the opportunity to look into quality: checking viral load trends intensively, training nurses, evaluating resistance patterns and fighting with (but more accurately for) non-adherent patients. And then all too soon I left behind the teenager who kept me busy on Mxit but lied to my face about adherence, and the many others who influenced my thoughts on HIV in one way or another. Unfortunately, I still bump into them every now and then in Pick ' $n$ Pay or at the local nursery, where I get an update on $\mathrm{CD} 4{ }^{+}$counts from mom and the grades of her healthy little boy.

\section{‘But most importantly, I saw life after HIV: a man on death's door walking back to work in a few months; a skeleton of a child smiling with her new toy after a few weeks of antiretrovirals; and Venus, who encouraged me at every consultation, despite being left blind and in a wheelchair ...'}

And lastly, after seeing one too many a sick child not cared for by mom, another unplanned pregnancy, the dreaded positive polymerase chain reaction test in a 6-week-old baby, there came a point when I started asking, 'What now?', 'Where to from here?', 'How do we stop this?' And that is when the red ribbon started to look more like an arrow pointing firmly towards HIV-prevention research. I am now privileged to be involved in two promising phase-three trials looking at conquering the transmission of HIV in females. There are, however, days when I feel like pointing the red-tipped arrow firmly at the participants (figuratively speaking, of course) who indulge in risky behaviour after the team's best counselling efforts. Fortunately though, I mostly see the big picture of South Africa leading the world into 'Getting to Zero', with the red arrow firmly pointed towards the 'icilwane' ('gogga', virus).

S Afr J HIV Med 2014;15(1):27. DOI:10.7196/SAJHIVMED.1039 